\title{
Die (reën)boog na die sondvloed \\ (Gen 9:12-17)
}

\author{
H F Stander \\ Departement Antieke Tale \\ Universiteit van Pretoria
}

\begin{abstract}
The (Rain)bow after the deluge (Gen 9:12-17)

The Hebrew word which is used for "rainbow" in Genesis 9:13,16 can also be translated as an archer's "bow". It is interesting to note that all the ancient writers used the latter meaning ("war bow") in their interpretation of the Noah account, and not the meaning of "rainbow". The ancients often depicted God as a warrior God who had a bow and shot arrows at those whom He wanted to punish. After God had punished the people for their sins, he hung up his bow. The bow in the clouds is without a bow string, and this is to remind the people that God is now at peace with them. In this article the prevalence of this interpretation in the ancient world, is shown. The writings of the Church Fathers are also scrutinized for their remarks on the (rain)bow. To conclude, the translation of this symbol in various Bible translations is also discussed.
\end{abstract}

\section{INLEIDING}

Hierdie feesbundel word opgedra aan drie gerespekteerde kollegas wat spesialiste in Semitiese Tale en in die Ou Testament is en was. My eie studieveld is die Patristiek. Dit het my laat besluit om met my artikel 'n brug te slaan tussen bogenoemde studievelde. Ek wil dus graag in hierdie artikel aantoon hoe kennis van buite-Bybelse bronne, en die Patristiek in die besonder, nuwe lig kan werp op die verstaan van 'n bekende OuTestamentiese teks. 
Ons lees in Gen 9:13,16 soos volg: "My rë̈nboog het Ek in die wolke geplaas. Dit sal die teken wees van die verbond tussen My en die aarde .... en wanneer Ek dit sien, sal Ek dink aan die ewige verbond tussen My en al die lewende wesens op die aarde." Die Hebreeuse woord wat hier met "reënboog" vertaal word, is קָשֶֶת. Maar die Wֶֶֶֶת word nie net gebruik om na die "reënboog" te verwys nie, maar ook om na die "boog" van 'n boogskutter te verwys (soos in pyl en "boog”). Ook in die Septuaginta word die Hebreeuse woord $q \check{s} t$ in hierdie Genesis-verhaal met Tó $\xi_{0 \nu}$ ("boog” van 'n boogskutter) vertaal. Daar is enkele gevalle in die Griekse letterkunde waar Tó $\xi_{0 \nu}$ wel met "reënboog" vertaal kan word (Liddel \& Scott 1961:1805), maar gewoonlik word die woord î $\rho$ s gebruik wanneer daar na laasgenoemde verwys word. Ook die woord arcus, wat in die Vulgaat in Genesis 9 gebruik word, kan na 'n "reënboog" of na 'n "boog van 'n boogskutter" verwys (Lewis 1987:155). Die woord iris vir "reënboog” kom ook in Latyn voor. Ons sien dus dat die Hebreeuse, Griekse en Latynse teks van Genesis 9:13, 16 telkens 'n woord gebruik wat beide die betekenis van "reënboog” en "boog van 'n boogskutter" dra.

In hierdie artikel sal aangetoon word dat, terwyl moderne eksegete in hulle interpretasie van Genesis 9 feitlik deurgaans werk met die betekenis van "rë̈nboog", die antieke outeurs telkens hulle interpretasie gebou het op die betekenis van 'n "krygsboog". In die antieke wêreld is 'n God wat straf dikwels as 'n krygsgod uitgebeeld. Die antieke outeurs het gesê dat nadat God sy volk met die sondvloed gestraf het, Hy sy krygsboog in die hemel opgehang het. Hierdie boog het nie 'n snaar nie, en ook geen pyle nie. Dit toon aan dat God Homself voorgeneem het om nie weer sy mense met 'n watervloed te straf nie.

Daar word gewoonlik aanvaar dat Wellhausen (1883) die eerste persoon was wat in die moderne tyd die krygsboog-motief verdedig het (kyk Turner 1993:119). In die daaropvolgende dekades het hy sporadies steun gekry vir sy standpunt. Von Rad (1976:101) sê byvoorbeeld "Das hebr. Wort, das wir mit Regenbogen übersetzen, bedeutet sonst im Alten Testament den Kriegsbogen. Damit ist eine Vorstellung von altertümlicher Schönheit gegeben: Gott zeigt der Welt, daß er seinen Bogen beiseitegestellt hat." Tog aanvaar die meeste moderne kommentatore steeds nie hierdie verklaring nie (kyk Van Selms 1967:124-125; Gispen 1974:299-300; Westermann 
1974:634-640; Wenham 1987:196). Maar daar is ook ander moderne eksegete wat sê dat ons nie regtig kan weet watter een van hierdie betekenisse in hierdie verhaal meespeel nie (Roop 1987:72; vgl ook Mathews 1996:410-411), terwyl ander selfs nie eens die moontlikheid vermeld dat ons hier met 'n krygsboog te doen het nie (vgl byvoorbeeld Maher 1982:74-75; Sacks 1990:67; Alter 1996:39; Speiser 1983:59). In hierdie artikel sal daar aangetoon hoe wyd verspreid in die antieke wêreld die krygsboogmotief in werklikheid was. Daar sal verder aangetoon word dat hierdie motief presies inpas in die antieke wêreldbeeld van 'n God wat oordeel. Hierdie interpretasie sal van verskillende invalshoeke belig word, en veral ook vanuit die Patristiek.

Tot op hede is daar bitter min aandag gegee aan wat die kerkvaders oor die "boog" van Genesis 9 gesê het. Lewis (1968) het byvoorbeeld in sy grondige studie oor hoe die verhaal van Noag en die Vloed in die Joodse en Christelike literatuur interpreteer is, die tema van die reënboog feitlik geheel en al ignoreer. Daar kon selfs nie eens 'n enkele plek opgespoor word waar Lewis in sy breedvoerige studie verwys na hoe vroegChristelike outeurs die boog-motief verstaan het nie. Dit is onverklaarbaar hoekom hy al die elemente van die Noag-verhaal in detail bespreek, maar die reënboog bloot buite rekening laat. Dit is dus nodig dat daar in hierdie artikel ook na die kerkvaders se standpunt oor die boog gekyk word, en daar sal voorgestel word dat die krygsboogmotief dalk meer ernstig oorweeg moet word in ons interpretasie van hierdie mitiese verhaal.

\section{GOD AS 'N KRYGSGOD IN DIE OU TESTAMENT}

Daar is natuurlik 'n hele paar plekke in die Ou Testament self waar God as 'n Krygsgod voorgestel word. So lees ons byvoorbeeld in Hab 3:8-9 die volgende: "Was U kwaad vir die riviere, Here? Het u toorn teen die strome ontvlam? Het die see U woedend gemaak dat $U$ op $u$ perde gery het, op die strydwaens waarmee $U$ oorwin? $U$ het $u$ boog uitgehaal en met 'n eed die opdrag aan die pyle bevestig. Sela." Robertson (1990:232233) skryf soos volg oor hierdie gedeelte: "This dramatic imagery of God's riding as a mighty warrior on horses and chariots to conquer his enemies appeared regularly in Israel's traditions." Hy verwys verder na die frase "U het u boog uitgehaal" en sê dan "The emphatic conjoining of a noun and a related verb to describe God's laying bare his 
bow dramatizes this action by which the divine Warrior readies himself for attack against his enemies. The positioning of the noun ('eryâ) before the verb ( $\left.t \bar{e}^{-} \hat{o} r\right)$ strengthens the thought."

Daar is al baie geskryf oor die moontlike mitologiese agtergrond van hierdie verhaal. Sommige geleerdes (vgl Robertson 1990:232-233) wil dit interpreteer teen sekere Ugaritiese verhale, terwyl ander weer Kanaänitiese mitologieë of selfs die Babiloniese mite van Enuma Elish wil gebruik om bogenoemde versgedeelte uit Habakuk te verklaar. Vir die doeleindes van hierdie artikel is dit egter nie belangrik om te weet watter mite ons agter hierdie verhaal moet raaklees nie. Die belangrikste is net om te weet dat die uitbeelding van God as 'n Krygsgod nie vreemd was in die tradisies van Israel nie.

Ook in Klaagliedere 2:3-4 lees ons: "Toe die vyand kom, het die Here sy magtige hand teruggetrek en sy toorn teen Jakob laat brand... Soos 'n vyand het Hy sy boog gespan en aangelê...”. Die bedoeling van hierdie teks is om te sê dat Jahwe in sy woede nou soos 'n vyand geword het. Sy beskerming het nou omgesit in 'n vyandige gesindheid jeens Israel. Ook in hierdie gedeelte word Jahwe dus as 'n Krygsgod uitgebeeld wanneer daar oor sy toorn gepraat word.

In Psalm 7:12-14 lees ons die volgende: “God is 'n betroubare regter, 'n God wat altyd die skuldiges straf. Hy maak sy swaard elke keer weer skerp, Hy span sy boog en lê aan. Hy hou dodelike wapens gereed en maak vir Hom brandpyle." Craigie (1983) skryf soos volg oor hierdie psalm: "The description of God's potential violence against the unrepentant sinner is pursued in the military terminology which characterized the earlier part of the psalm; ... "He sharpens his sword" (gets it ready for action) and "has bent his bow" (analogous to cocking a pistol), and the flaming arrows are all ready for shooting".

\section{DIE BOOG IN MITOLOGIESE VERHALE}

Skinner (1976:173) wys daarop dat mens die boog in etlike mitologiese verhale aantref. Onder die Arabiere tref mens Kuzah aan wat pyle uit sy boog geskiet het en dit toe in die wolke opgehang het. By die Indiërs kry mens die krygsboog van Indra, wat hy eenkant neersit na sy stryd met die demone. In die Babiloniese skeppingsmite Enuma Elish (vi, 
84) word Marduk se boog, nadat hy dit teen Tiamat en haar bondgenote gebruik het, in die hemele as 'n konstellasie sterre opgestel (vgl Turner 1993:120).

Gegewe die feit dat die eerste elf hoofstukke van Genesis 'n sterk mitologiese karakter het, is dit nie onmoontlik nie dat die mitiese verhaal van 'n god wat sy krygsboog in die hemel ophang nadat hy die mense gestraf het, terug te vind is in die Noag-verhaal.

\section{IKONOGRAFIE}

Klingbeil (1999) gee in sy studie talle voorbeelde van waar die God van die hemel in die Antieke Nabye Ooste as Krygsgod uitgebeeld is. 'n Bestudering van hierdie ikonografiese materiaal sal mens ook help om baie van die krygsbeelde in die Psalms beter te verstaan. Die belangrikste bron vir al hierdie uitbeeldings is Neo-Assiriese silinderseëls. Keel sê dan ook dat miniatuurkuns die belangrikste massa kommunikasiemedium in Palestina/Israel was (kyk Klingbeil 1999:166).

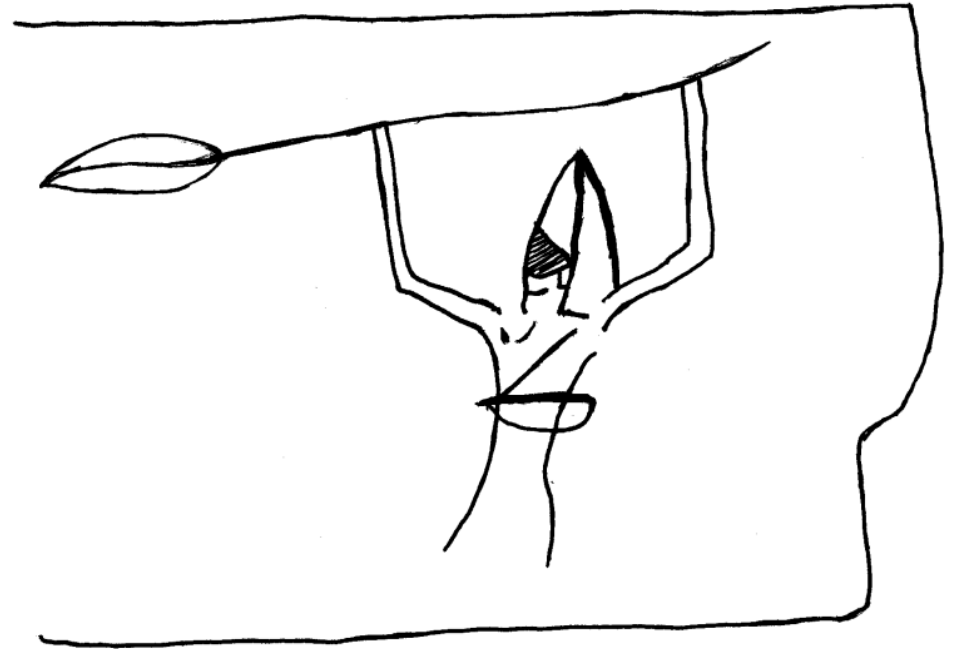

Fig 1

Mens kan die voorstellings van die Krygsgod in verskillende kategorieë verdeel. In die eerste plek is daar talle uitbeeldings van 'n God wat met 'n swaard of knuppel slaan. In die tweede plek is daar voorstellings van 'n god met ' $\mathrm{n}$ spies in die hand (kyk byvoorbeeld figuur 1). Ander kere weer is die godheid uitgebeeld waar hy 'n hele klomp 
wapenrusting dra. Ons kry ook etlike voorbeelde van 'n godheid wat 'n bundel weerligstrale in sy hand dra. Hier word die krygsmotief dus verder uitgebrei en word weerlig as 'n meteorologiese wapen gebruik.

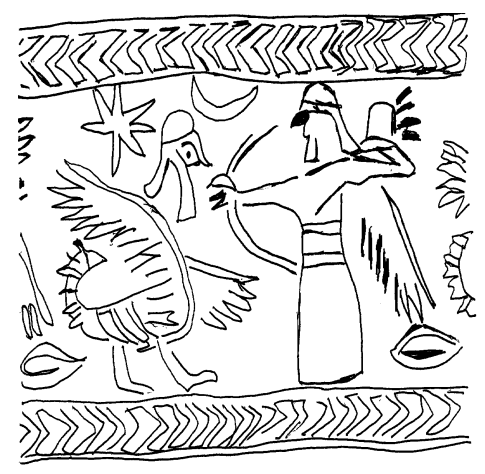

Fig 2

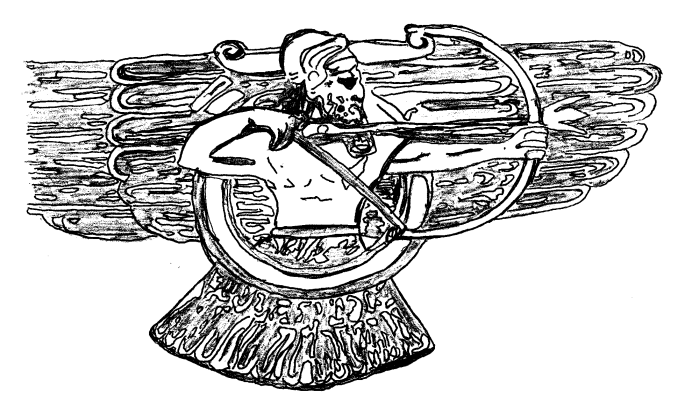

Fig 3

Maar dan is daar ook afbeeldings van 'n God wat as 'n boogskutter uitgebeeld word. So sien ons byvoorbeeld in figuur 2 'n Godheid met 'n gespanne boog in die hand wat mik na een of ander lewende wese. In figuur 3 het ons 'n afbeelding van 'n god wat besig is om 'n pyl te skiet. Die pyl het 'n drie-ledige punt en is simbool van 'n weerligstraal. Agter die god se rug kan mens die bokant van 'n koker vir sy pyle sien. Hierdie afbeelding is gevind op 'n reliëf van die Noord-Westelike Paleis van Asshurnasirpal II (883-859 vC).

Ook die ikonografie wys vir ons hoe algemeen dit was om 'n god uit te beeld met wapens in sy hand.

\section{JOODSE TRADISIE}

Die Joodse eksegeet Philo (Quaestiones in Genesim ii. 64) sê dat hy absoluut oortuig is dat wanneer God sê "Ek het my boog in die wolke geplaas" (Gen 9:13), God nie van 'n gewone reënboog praat nie. Hy voer twee redes aan vir sy standpunt. In die eerste plek wys hy daarop dat 'n reënboog nie werklik bestaan nie, maar dat dit bloot iets is wat mens waarneem wanneer die son se strale op die wolke skyn. Omdat God na die boog as 
"my boog" verwys, en omdat Hy dit in die wolke geplaas het, moet mens daaruit aflei dat hier van 'n werklike boog gepraat word. In die tweede plek, so redeneer Philo, sal mens nooit 'n reënboog in die nag sien nie, en ook nie as dit baie bewolk is nie. In Genesis 9:13, daarenteen, lees ons dat God sy boog "in die wolke” plaas. Mens kan dan nie anders nie (volgens Philo) om daaruit af te lei dat God se boog geen reënboog is nie. Derhalwe besluit Philo om veel eerder die krygsboog as beeld te gebruik wanneer hy hierdie versgedeelte verder kommentarieer.

Dit is wel so dat mens nie Philo as 'n gesaghebbende eksegeet kan aanhaal nie. Tog bevestig Philo se kommentaar vir ons hoe wydverspreid die beeld van die krygsboog wel was. Buitendien, dieselfde beelde kom ook elders in Joodse tradisies voor. So lees ons in die Wysheid van Salomo (5:20-21) die volgende: "En sy strenge toorn sal Hy skerpmaak tot 'n swaard... Die goedgemikte pyle van die bliksems sal trek, en soos uit 'n goedgespanne boog van wolke tref hulle die doel.” Ook in 4 Esdras 16:13 lees ons: "Want sy regterhand wat die boog buig, is sterk, en die pyle wat Hy skiet, is skerp en sal nie hulle teiken mis wanneer hulle afgeskiet word na die eindes van die wêreld nie."

Die beeld van God as 'n Krygsgod wanneer hy mense straf, is dus nie vreemd aan die tradisies van Israel nie.

\section{DIE KERKVADERS}

Een en elke kerkvader gebruik die beeld van 'n krygsboog wanneer hulle kommentaar lewer op die Noag-verhaal. Ambrosius (Liber de Noe et Arca 27,104) sê dat dit belangrik is om daarop te let dat God 'n krygsboog in die wolke geplaas het, en nie 'n pyl nie. Hy wys daarop dat die krygsboog bloot 'n instrument is waarmee 'n mens 'n pyl afskiet. Die boog self kan niemand seermaak nie. Dit is egter die pyl wat mense verwond. Maar God het die boog in die wolke gesit omdat dit 'n aanduiding bied van vrees.

Elders lewer Ambrosius kommentaar op Psalm 43(44):8 ("U het ons verlos van ons teëstanders en ons haters beskaamd gemaak", Enarratio in Psalmum xliii,20). Hy verduidelik dan dat God hulle juis van hulle teenstanders verlos het deur pyle uit die hemel te skiet. Dit het tot gevolg gehad dat die hele aarde tot bedaring gekom het. Ambrosius bring dit dan in verband met wat ons in Psalm 75(76):4, 9 lees: "Daar het Hy die blitspyle van die boog verbreek, skild en swaard en oorlog .... Uit die hemel het U 'n 
oordeel laat hoor; die aarde het gevrees en stil geword." Ambrosius dink dus ook aan God as 'n boogskutter wanneer hy praat van God se oordeel.

Ambrosius (Enarratio in Psalmum xxxvi (xxxvii), 27) sê dat toe God 'n boog in die hemel geplaas het, die vloedwaters gewyk het, en daar het weer vrede en kalmte neergedaal. Hierdie boog in die Noag-verhaal word dan vir Ambrosius 'n bewys dat die Bose presies die teenoorgestelde doen. Die Bose span sy boog sodat hy storms in ons kalm gemoedere kan opjaag. Ons kry presies hierdie selfde gedagte by Origenes (Excerpta in Psalmos, PG 17:129). Ook Origenes sê dat toe God sy boog in die wolke geplaas het, die storm opgehou het, en die vloed tot 'n einde gekom het. Die Bose, daarenteen, gebruik sy boog om kalmte en vrede tot 'n einde te bring, en oorlog aan te hits.

Origenes (Selecta in Psalmos, PG 12:1181) redeneer dat omdat God sê "Ek is die Lewe" (vgl Joh 14:6), sal Hy tog nie sy boog as 'n voorwerp van dood gebruik nie. Hy plaas dus sy boog in die hemel om 'n einde te bring aan die vloedwater op die aarde. Origenes voeg by dat dit net die duiwel is wat sy boog gebruik as 'n instrument om dood te maak. Elders (Excerpta in Psalmos, PG 17:129) argumenteer Origenes nes Ambrosius dat God met sy boog reënstorms tot bedaring bring. Daarenteen, sê Origenes, is satan daarop uit om met sy boog die kalmte van die siel tot einde te bring, vrede te blus, en oorlog aan te hits.

Basilius (Homiliae super Psalmos, PG 29:245) sê dat wanneer ons sien dat mans besig is om hulle wapens blink te vryf, moet mens sommer weet dat daar 'n oorlog aan die kom is. Presies net so moet ons weet dat God op die punt is om mense te straf as die Woord sê dat God se swaard skitter. Basilius voeg by dat ons ook moet verstaan dat dit is wat bedoel word wanneer daar van God se boog gepraat word, omdat God se boog 'n instrument van dood is. Hy sê verder dat dit nie 'n boogsnaar is wat God se krygsboog laat span of ontspan nie, maar wel sy mag om te straf.

Ook Chrysostomos (In venerabilem crucem sermo, PG 50:818) sê dat ons moet weet dat God se boog 'n instrument van dood is. Maar dit beteken hoegenaamd nie dat God ons met sy boog wil veroordeel nie. God wil maar net nie hê ons moet ongeërg word en geestelik verslap nie. Chrysostomos sê dat daar geen sprake daarvan is dat God 
die mense wil vernietig nie. 'n Mens kan dit duidelik sien uit die feit dat Hy bereid was om sy bloed vir die mense te laat vloei.

Victorinus van Pettau (Commentarius in Apocalypsim 3) skryf in sy kommentaar op Openbaring dat daar 'n reënboog om God se troon is. Hy sê dat hierdie troon nes 'n reënboog baie kleure het. Maar dan wys hy daarop dat in die Noag-verhaal God se reënboog 'n krygsboog genoem word. Hy sê dit word so genoem sodat die mense nie meer hoef te vrees dat hulle in 'n reënstorm vernietig sal word nie.

Wanneer ons sê dat die kerkvaders die boog in die Noag-verhaal as 'n krygsboog verklaar het, beteken dit nie dat hulle ontken dat daar 'n reënboog was nie. Maar omdat die een Hebreeuse (asook die Griekse en Latynse) woord beide "reënboog" en "krygsboog" kon beteken, kon hulle maklik die krygsboogmotief betrek in hulle interpretasie. Die kerkvaders self het nie bloot 'n mitiese of primitiewe konsep gehad van wat 'n reënboog in werklikheid was nie. Hulle het per geleentheid heel wetenskaplik gepraat oor wat dit is wat maak dat mens 'n reënboog sien (sulke wetenskaplike verklaring is natuurlik in terme van hulle kontemporêre wetenskapskennis gedoen). Basilius (Epistula xxxviii) sê byvoorbeeld dat die kenners van sy tyd beweer dat 'n reënboog gevorm word wanneer vog met lug vermeng. Hy verduidelik dan dat 'n reënboog gevorm word wanneer 'n sonstraal 'n digte en donker deel van 'n wolkformasie binnedring. Die son gooi dan sy eie sferiese vorm op 'n wolk, en dan word die glans daarvan terug gereflekteer na die mens toe.

\section{SLOTOPMERKINGS}

In die lig van bogenoemde moet ons sê dat die motief van die krygsboog wel moontlik meespeel in die Noag-verhaal. Dit was immers 'n baie algemene konsep in die antieke wêreld dat God pyle afskiet wanneer Hy oordeel of straf. Die woord wat vir "boog" gebruik word in die Hebreeuse, Griekse en Latynse tekste dra ook gewoonlik die betekenis van krygsboog. Verder is dit ook duidelik dat dit die interpretasie is wat die antieke Skrifverklaarders hieraan gegee het.

Die argumente van moderne Skrifverklaarders wat hierdie interpretasie verwerp, is nie baie oortuigend nie. Von Rad (1976) sê byvoorbeeld dat die antieke opvatting eintlik baie mooi is, omdat God aan die wêreld wys dat Hy sy boog eenkant gesit het. 
Maar Van Selms verwerp Von Rad se siening, en sê dat as God sy boog tersyde gestel het, God sy boog sou ontspan het. Maar Van Selms kon gerus by die kerkvaders gaan kers opsteek het. Hulle argumenteer juis, soos ons hierbo gesien het, dat hierdie boog ontspan is omdat dit geen snaar of pyl het nie.

Westermann (1974) verwerp ook die krygsboogmotief en sê dat die krygsboogmotief geen aanknopingspunt vind in hetsy die teks, hetsy die konteks daarvan nie. Dit is onverklaarbaar hoe Westermann so kan argumenteer. Die Noag-verhaal handel dan juis oor God se straf op mense, en dit was heel algemeen in die antieke wêreld om 'n God wat straf uit te beeld as 'n soort krygsgod met 'n boog in die hand. Daar is dus wel 'n aanknopingspunt in hierdie verhaal vir die krygsboogmotief.

Die betoog van hierdie artikel is nie om te ontken dat Genesis 9 oor 'n reënboog handel nie. Die reënboog is natuurlik 'n belangrike element in die Noag-verhaal, maar die Hebreeuse woord dra hier 'n ambivalente betekenis. Ons moet dus ook die betekenis van "krygsboog" in ons interpretasie betrek om reg te laat geskied aan die teks.

Ten slotte: Dit is baie jammer dat die vertalers van die Nuwe Afrikaanse Vertaling Genesis 9:13 vertaal het as "My rë̈nboog het Ek in die wolke geplaas." Daarmee het hulle gepoog om hulle interpretasie van hierdie vers af te dwing. Dit sou beter gewees het om die uitleg van hierdie teksgedeelte meer "oop" te hou, en dit slegs met "boog" te vertaal het. Die vers is dan steeds heel duidelik, en ook ' $n$ baie getroue weergawe van die oorspronklike. Dit is immers een van die gesonde beginsels wat aan voornemende Bybelvertalers geleer word, naamlik om die oorspronklike vorm te behou, indien dit duidelik is, en ook nie misverstaan kan word nie. Dit is derhalwe opmerklik dat die meeste Engelse Bybelvertalings inderdaad die woord in Genesis 9:13 slegs met "bow" vertaal, en nie met "rainbow" nie. Mens dink hier aan Bybelvertalings soos die Authorised Version, Revised Standard Version, New Revised Standard Version, New Jerusalem Bible, New American Bible, New American Standard Bible, American Standard Version, en die Good News Bible. Mens hoop dat 'n volgende Bybelvertaling in Afrikaans reg sal laat geskied aan hierdie saak. 


\section{Literatuurverwysings}

Alter, R 1996. Genesis: Translation and commentary. New York: W W Norton \& Company.

Craigie, P C 1983. Psalms 1-10). Texas: Word Books. (Word Biblical Commentary, Vol 19.)

Forstner, D 1961. Die Welt der Symbole. München: Tyrolia-Verlag.

Gispen, W H 1974. Genesis: Vertaald en verklaard. Kampen: H Kok.

Klingbeil, M 1999. Yahweh fighting from heaven: God as warrior and as God of heaven in the Hebrew psalter and ancient Near Eastern iconography. Göttingen: Vandenhoeck \& Ruprecht.

Lewis, C T 1987. A Latin Dictionary. Oxford: Clarendon Press.

Lewis, J P 1968. A study of the interpretation of Noah and the flood in Jewish and Christian literature. Leiden: E J Brill.

Liddell, H G \& Scott, R 1961. A Greek-English Lexicon. Oxford: Clarendon Press.

Louth, A 2001. Genesis 1-11. Downers Grove: InterVarsity Press. (Ancient Christian Commentary on Scripture.)

Maher, M 1982. Genesis. Wilmington: Michael Glazier. (Old Testament Message.)

Mathews, K A 1996. Genesis 1-11:26. Broadman \& Holman Publishers. (The New American Commentary Vol. 1A.)

Nodes, D J 1991. Noah's rainbow in early Jewish and Christian exegesis. Australian Biblical Review 42(3), 236-250.

Robertson, O P 1990. The Books of Nahum, Habakkuk, and Zephaniah. Grand Rapids: Eerdmans,

Roop, E F 1987. Believers Church Bible Commentary. Scottdale: Herald Press.

Sacks, R D 1990. A commentary on the Book of Genesis. Lewiston: The Edwin Mellen Press. (Ancient Near Eastern Texts and Studies.)

Skinner, J 1976. A critical and exegetical commentary on Genesis. Edinburgh: T \& T Clark. (The International Critical Commentary.)

Speiser, E A 1983. Genesis, Introduction, translation and notes. New York: Doubleday. (The Anchor Bible.) 
Stoop, J A A A 1968. Noag en die ark in die vroeë Christendom en veral by Cyprianus. Theologia Evangelica 1(1), 26-29.

Turner, L A 1993. The rainbow as the sign of the covenant in Genesis ix 11-13. Vetus Testamentum 43(1), 119-124.

Van Selms, A 1967. Genesis, I. Nijkerk: Callenbach.

Von Rad, G 1976. Das erste Buch Mose Genesis. Göttingen: Vandenhoeck \& Ruprecht.

Wellhausen, J 1883. Prolegomena zur Geschichte Israels. Berlin: De Guyter

Wenham, G J 1987. Genesis 1-15. Waco: Word Books Publisher. (Word Biblical Commentary.)

Westermann, C 1974. Genesis, I. Neukirchen-Vluyn: Neukirchener Verlag des Erziehungsvereins. 